DOI 10.37882/2223-2982.2020.11.32

\title{
ДИСКУРСИВНЫЕ ФОРМУЛЫ РАЗГОВОРНОЙ РЕЧИ ПРИ ИЗУЧЕНИИ ИСПАНСКОГО ЯЗЫКА: ПРАГМАТИКА В РЕЧИ
}

\section{DISCURSIVE FORMULAS OF SPOKEN LANGUAGE WHEN LEARNING SPANISH: PRAGMATICS IN SPEECH}

\section{Ramírez Rodríguez Pablo}

Summary: Language reproduction is described as an interactive process consisting of a specific type of knowledge (Schiffrin: 2000). Such expressive and social communication skills that are related to each other include three types of skills: the cognitive ability to present concepts and ideas through language. Of these three skills, this paper focuses on textual abilities that include criteria for speech organization, as well as recognition of coherence and connectivity mechanisms.

Keywords: discursive formulas, colloquial speech, foreign language, pragmatics, discourse, speech acts.
$\mathrm{H}$ а первый взгляд, идентифицировать дискурсивные частицы в определенной коммуникативной ситуации может быть сложно. Кроме того, объект исследования находится в относительно новой языковой области и поэтому он мало известен на данный момент. В соответствии с термином «дискурсивный» у человека ожидается наличие всего лексического багажа языка, поскольку он постоянно его используем в процессе общения. Тем не менее, это группа небольших слов, чья семантическая нагрузка иногда настолько сложна, что затрудняет процесс перевода. Априори, эти единицы могут быть не очевидны в коммуникативном акте, однако они абсолютно необходимы как для говорящего, так и для собеседника, чтобы достичь прочного и связного дискурса.

Многим недавним исследованиям, которые посвящены области дискурсивных формул языка, предшествует ряд различных перспектив и определений, которые препятствуют согласию единодушного определения для этих дискурсивных единиц. Однако большинство исследователей согласны с тем, что эти единицы дискурса ориентированы и связаны с дискурсивной связностью (Renkema: 1999).

Большинство из этих единиц - это разговорные частицы, типичные для разговорного языка, которые мало изучены. Эти частицы принадлежат к культурному наследию говорящего, который воспроизводит их в определенном коммуникативном контексте, почти

\author{
Рамирес Родригес Пабло \\ Аспирант, РУДН, Москва \\ ramires-rodriges-p@rudn.ru
}

Аннотация: Воспроизводство языка описывается как интерактивный процесс, состоящий из определенного типа знаний (Schiffrin: 2000). Такие знания коммуникации выразительные и социальные, которые связаны друг с другом, включают в себя три типа навыков. Из этих трех навыков в данной работе интерес направлен на текстовые способности, которые включают в себя критерии организации речи, а также признание механизмов согласованности и связности дискурса.

Ключевые слова: дискурсивные формулы, разговорная речь, иностранный язык, прагматика, дискурс, речевые акты.

бессознательно. Это отражается в любом речевом акте, представляя последовательность открытия, закрытия или даже вставки в разговорах, которые мы ведем ежедневно, где дискурс приобретает значение, более связанное с контекстом, в котором он развивается (Berenguer: 1995).

В терминах концепции дискурсивной формулы утверждают, что «Формулы дискурса - это неизменные лингвистические единицы, функция которых заключается в том, чтобы указать («отметить») отношения, установленные между двумя текстовыми сегментами. Эти единицы не выполняют никакой синтаксической функции, но представляют собой надрегиональные связи, которые облегчают текстовое единство и интерпретацию предложений» (Zorraquino, Portolés: 1999).

Термин «дискурсивная формула» принадлежит C. J. Fillmore, который основал теорию“Грамматика конструкций". До появления программной статьи "Regularity and Idiomaticity in Grammatical Constructions: the Case of Let Alone" (Fillmore: 1988), положившей начало этой теории, C. J. Fillmore было написано еще две статьи: "On fluency. In Individual differences in language ability and language behavior" (Fillmore: 1979) и "Remarks on contrastive pragmatics. Contrastive linguistics: Prospects and problems" (Fillmore: 1989). В первой статье говорится о роли лингвоспецифичных фиксированных выражений, а во второй рассматривается доказательство возможности сравнения прагматических явлений в разных языках. 
Если сопоставить дискурсивные формулы с конструкциями, то главное отличие заключается в отсутствии синтаксиса внутри них, так как они уже полностью прошли путь прагматикализации. Обычные конструкции содержат в себе слоты, которые заполняются переменными. В Конструкции «What's X doing Y?» (Kay, Fillmore: 1999), как в предложении «What is this fly doing in my soup?» видно, что место переменной $X$ занимает некоторый субъект или объект, а позицию $\mathrm{Y}$ - место, в котором $\mathrm{X}$ не должен находиться. Таким образом, следующее предложение неприемлемое «What is this soup doing in my fly?» A поскольку все элементы у дискурсивных формул фиксированы, в них таких переменных нет.

В связи с семантикой у обычных конструкций задается формула: предикатное слово со своей аргументной структурой. В случае дискурсивных формул ситуация совсем другая: даже если в формуле есть предикат, он ведет себя нестандартным образом. В двух словах дискурсивная формула представляет собой целое законченное предложение, которое характеризуется прагматической интонацией и отображает иллокутивную силу жестикуляцией.

Как уже упомянуто выше, дискурсивные формулы, в отличие от обычных конструкций, в большой степени принадлежат к области прагматики. Из этого вытекает, что дискурсивные формулы следует классифицировать как особые речевые акты. Одновременно, контексты, в которых они появляются, тоже являются ничем иным как речевыми актами.

Каждой дискурсивной формуле приписывается антецедент, т. е. стимул для ее произнесения (Fillmore: 1989). Таким образом, это главная особенность описания дискурсивных формул, в отличие от конструкций. Более того, C. J. Fillmore отметил, что такие выражения представляют хороший пример языковых единиц, у которых вовсе нет семантики, так что связь между прагматикой и синтаксисом осуществляется напрямую. Если это верно, то при описании дискурсивных формул следует опираться на классификацию речевых актов так же, как обычно лексикографы опираются на семантические классификации языковых единиц при анализе их употреблений. Поэтому, в первую очередь, необходимо разработать специальную прагматическую разметку для антецедентов, но при этом, различая антецеденты, которые являются вопросами, утверждениями и императивами, в отдельных случаях представляем прагматическую информацию об антецеденте.

Ярким примером появления дискурсивной формулы будет разговор о погоде, где человек часто выбирает стереотипные и почти ритуализированные диалоговые формулы с ценностью одобрения на то, что сказал говорящий, данные формулы удобны для такого контекста.
Таким образом, перед утверждением “кажется, что пойдет дождь" (ucn. Parece que va a llover) могут быть выделены следующие дискурсивные формулы в ответ: "так кажется", “похоже на то", "это правда", “это точно”, или в испанском языке "pues sí", "eso parece", "parece que sí" и т. д. Кроме того, в ходе разговора и другие факторы несомненно играют важную роль в коммуникативной ситуации, такие как: интонация, просодия и жесты, которые часто сопровождают эти единицы, что также могут оказывать положительное или отрицательное влияние в соответствие с контекстом.

В дополнение к этим элементам, которые сопровождают дискурс, мы не можем забыть о важности прагматической ценности, которая подчеркивает возможные значения или интерпретации дискурса. Цель дискурсивных формул - указать функцию и облегчить обработку и производство дискурса. Они отличаются, главным образом, функционированием.

В то же время, когда началось изучение этих сложных единиц, то было замечено, что на разных языках в контексте они выглядят по-разному, а также частота их использования варьируется в зависимости от контекста. Таким образом, в русском языке можно подумать, что все дискурсивные единицы принадлежат к разговорному языку. Однако они часто появляются даже в научных текстах, чтобы привлечь внимание читателя. С другой стороны, английский стремится к упущению этих единиц, поскольку считается, что им не хватает стиля, и поэтому их следует избегать.

Описываемый тип языковой дивергенции является основной причиной, которая приводит к стилистическим ошибкам, неизбежным даже при наличии словарей. Поэтому с лексикографической точки зрения разрешить эти пробелы в области дискурсивных маркеров является амбициозным решением, поскольку достигнутые к настоящему времени успехи скромные и выступают в качестве одноязычного словаря.

Особенность этих разговорных дискурсивных единиц заключается в сложности объяснения истинного смысла, поскольку она не исходит из самой дискурсивной формулы, а требует определенного контекста. Возможно, сложность их интерпретации заключается в том, что большинство этих формул дискурса включают в себя формы, принадлежащие нескольким грамматическим категориям, которые не работают в качестве прототипов этих категорий. Таким образом, hombre, vamos, anda или venga не используются в соответствии с их природой, то есть они не принадлежат ни к вербальной форме, ни к существительному, но эти случаи претерпели трансформацию, превращаясь в диалоговые маркеры.

- Мне нужна срочно твоя помощь, иначе не смогу до- 
писать статью! - вот ещё! Ты мне никогда не помогал, а теперь я должен тебе помочь?

(Отказ на предложение или просьбу) - necesito tu ayuda urgentemente, si no no podré terminar el artículo. -Si hombre! Tú nunca me has ayudado, ¿y yo ahora tengo que ayudarte?

В случае русского языка, объяснение перед дискурсивными формулами "в чем дело?», «а в чем тогда дело?" и «в чем дело-то?», выведено, как и в испанском языке, из определенной деградации во время разговора. Первый вариант нейтрален: после того, как начался разговор, собеседник хочет узнать, что происходит, и задает следующий вопрос: (а) В чем дело? (Исп. ¿Qué pasa? букв. что проuсходum?). Во втором варианте заметно появление нового элемента, наречие тогда, которое показывает предыдущую и безуспешную попытку говорящего узнать ответ на вопрос, и он снова спрашивает (б) А в чем тогда дело? (Исп. ¿Entonces qué раsа? букв. тогда что nроисходum?) В третьем примере видно, что сообщение не является плодотворным и что говорящий, столкнувшийся с ранее неудачными попытками, все еще игнорирует этот вопрос, поэтому он вынужден задавать один и тот же вопрос, но более строгим тоном и с появлением укрепляющего элемента -то, (в) В чем дело-то? (Исп. ¿Pero entonces qué pasa? букв. но тогда что происходит?)

(2) - Так. А в чём дело? - опомнился Егор. - Не понимаю, объясни, пожалуйста. [Василий Шукшин. Калина красная (1973)]

(3) - Да я совсем не про то... - А в чём тогда дело? Он понял, что Орли притащила его к себе в дом вовсе не потому, что пожалела одинокого пьяного человека посреди холодной Москвы. [Алексей Иванов. Комьюнити (2012)]

(4) -А в чём дело-то? - спросил он обиженно, шёпотом. [Василий Шукшин. Калина красная (1973)]

Все это говорит о том, что что-то, кажущееся таким простым и существующим на других языках, не должно оставаться незамеченным. В этих примерах отмечается, что на испанском языке, хотя и с проявлением некоторых особенностей, существуют эквиваленты для каждого из предложенных ранее вариантов на русском языке. Проблематика начинается, когда появляются русские формулы, в которых используется одна и та же дискурсивная формула в разных контекстах, затрудняя интерпретацию значения формулы в каждом контексте и, следовательно, перевод на испанский язык.

Во время изучения иностранного языка очень часто встречаются ситуации, в которых мы не знаем как реагировать, особенно в ситуациях общения, таких как ежедневное принятие извинений или просто ответ на благодарность. Если преподаватели будут помнить и наблюдать за учениками это ежедневно, то можно увидеть, что существует много неудобных ситуаций, вызванных недостатком знаний определенных формул социального взаимодействия, с которыми сталкиваются студенты иностранного языка, особенно на начальных уровнях, когда они не знают, как реагировать на приветствие, презентацию или поздравление в ходе ежедневных взаимодействий.

В повседневной жизни каждый человек находится в окружении ситуаций общения, в которых используются выражения, многие из них фиксированные и идиоматические, составляющие часть социальных взаимодействий говорящих на испанском языке и без которых общение может быть затруднительно. Знание этих фразеологических единиц, которые используются заранее определенным и институционализированным способом может помочь изучающим второй язык улучшить их способность к взаимодействию в большинстве повседневных ситуаций и, следовательно, их коммуникативную компетентность в испанском языке, такую как формулы рутина.

Исходя из вышесказанного, дискурсивные формулы являются лингвистическим отражением привычных ситуаций общения. Они являются выражениями, которые установлены социокультурно из-за их многократного использования в определенных повседневных ситуациях, пока они не становятся неотъемлемой частью развития определенных разговорных обменов между спикерами сообщества (Corpas: 1996).

Эти формулы по умолчанию используются докладчиками в социальных коммуникативных ситуациях для приветствия, извинения, благодарения, обещания и т.д. или с функцией открытия, закрытия или перехода в речи. Таким образом, будучи связанными с конкретной ситуацией и составляющими лингвистически и социально установленные элементы, они становятся частью лексического компонента выступающих и становятся необходимыми для обеспечения коммуникативного успеха и прагматической и социокультурной адаптации в коммуникативном обмене. Как показано ранее, по отношению к лексическому подходу говорящие сохранили в ментальном лексиконе эти минимальные единицы коммуникации в целом и в конкретных ситуациях используют их и интерпретируют как таковые.

Кроме того, тот факт, что они определяются коммуникативной ситуацией, делает их предсказуемыми в определенных контекстах. Таким образом, по словам G. Corpas, «они способствуют быстрой обработке языка, так что говорящие могут тратить больше времени на планирование более длинных единиц речи и заботу о социальных аспектах общения» (Corpas: 1996), и, с другой стороны, как объясняет J. В. Yagüе, «они одобряют принцип комфорта, потому что говорящий не вынуж- 
ден разрабатывать всю свою речь, а использует эти заранее установленные формулы, которые распознает его собеседник и которые ведут к более быстрой и более эффрективной коммуникации» (Yagüe: 2003).

Все эти характеристики, которые упомянуты выше, делают формулы разговорной речи достижимой целью обучения для учеников начальных уровней и очень прибыльными в их социальных взаимодействиях, учитывая, что они не обладают сильным знанием нового языка, то они обеспечат им беглость и уместность, а также помогу получить прагматичный результат, будучи в состоянии сосредоточить свои усилия на создании новой информации, которую они хотят предложить, а не столько на разработке этих коммуникативных актов. Из того, что на данный момент связано с процессом преподавания и обучения, можно выделить две характеристики рутинных формул: их предсказуемость и тот факт, что они кажутся связанными с ситуациями социального взаимодействия. Зная об этом, преподаватели могут работать над ними в классах, предвидя их потребности в соответствии с лингвистическими функциями, которые они имеют в качестве цели обучения и всегда сопровождают их контекстом использования в коммуникативных обменах.

Согласно R. D. Lewis (1997), учитель должен помочь ученику осознать эти сегменты, которые будут способствовать отражению и усвоению как лексических элементов, так и фонологических и грамматических аспектов. Фактически, еще один из принципов, на которых основана эта теория - это концепция, что язык сформирован грамматизированной лексикой, то есть эта идея основана на «принципе идиоматичности». При понимании языка как набора готовых блоков эти сегменты должны преподаваться с лексической точки зрения, то есть без их внутреннего анализа, особенно в первые моменты, фундаментальная проблема для работы с обычными формулами с начальных уровней.

Во время работы с обычными формулами в классе, их обучение в контексте должно поощряться, чтобы способствовать развитию, в то же время, коммуникативной и межкультурной компетенции обучающихся испанского языка. В ходе осуществляемой деятельности и практики преподаватели должны учитывать не только формальные характеристики рутинных формул, такие как их возможная фиксация и идиоматичность, но также такие вопросы, как реестр, к которому они принадлежат, или частота использования, уровень обучения, в котором можно работать на основе вышеупомянутых характеристик и коммуникативных функций, которые являются лингвистическим показателем или культурным содержанием, которые мы намереваемся рассмотреть, а также межкультурные аспекты, которые мы хотим отразить.

\section{Зак^ючение}

На протяжении всей истории проверялась актуальность дискурсивных маркеров в разговоре коммуникативного и социального взаимодействия, задача которого состоит в том, чтобы структурировать дискурс, не только упорядочивая компоненты аргумента, но и служить руководством для семантического умозаключения, направляя рассуждения во время разговора и устанавливая различные отношения, будь то инициация, причинность, сложение, преемственность, оппозиция, согласие или закрытие (Portolés: 2009). Кроме того, они способствуют согласованности, сплоченности и логическому развитию разговора. В этой работе проанализирована проблема наиболее часто используемых разговорных дискурсивных формул, приписывая новое лексическое видение испанскому языку с семантико-прагматической точки зрения. Таким образом, можно сделать вывод, что семантические и прагматические свойства не могут быть отделены от функций, которые они выполняют в дискурсе, особенно при анализе прагматического компонента, так как необходимо учитывать как внешнюю прагматику текста, так и внутреннюю.

Изучение фразеологических единиц этого типа способствует развитию коммуникативной компетенции, которая является основной целью процесса преподавания и изучения второго языка, в данной работе рассмотрен испанский язык. Мы считаем, что учащийся осуществляет эффективное взаимодействие на испанском языке, когда его участие в коммуникативном обмене является успешным, то есть когда он использует необходимый лингвистический контент, адаптируя свою продукцию к коммуникативной ситуации и принимая во внимание контекст. В этом смысле, для того чтобы общение было эффективным, важно, чтобы выбор лексических единиц, в данном случае обычных формул, которые выполняет учащийся, соответствовал лингвистическим функциям, которые происходят в этом взаимодействии с социокультурной, прагматичной и дискурсивной точки зрения.

С другой стороны, необходимо помнить, что этот успех во взаимодействии, в свою очередь, усилит эффективный компонент обучения, который непосредственно повлияет на улучшение процесса обучения и представление ученика о себе как о говорящем.

В ходе работы сделан вывод, что дискурсивные формулы, будучи фразеологическими утверждениями, представляют собой сложные лексические единицы, которые студенты будут понимать как лексические сегменты, а их использование способствует обучению и выработке беглости и правильности речи говорящего при взаимодействии на испанском языке; когда это связано с ситуациями социальной коммуникации. В некоторых случаях 
доступны различные варианты формулы, что улучшит качественные знания лексики и будет способствовать адаптации к обучению студентов использованию в контексте. Составляя лингвистические функции и являясь частью ситуативных взаимодействий, они могут легче усваиваться учащимися посредством как косвенного, так и прямого обучения.
Мы должны учитывать как студенческую культуру, убеждения, языковые особенности, социокультурные привычки и обычаи, так и те, которые типичны для обществ, в которых говорят на испанском языке, и содействовать работе, в которой обе культуры присутствуют в глобальном развитии студента как говорящего на испанском языке.

\section{ЛИТЕРАТУРА}

1. Berenguer J.A. (1995) “Marcadores discursivos y relato conversacional". Caplletra. Revista Internacional de Filologia, (18), 109-120.

2. Corpas Pastor G. (1996) "Manual de fraseología". Gredos, Madrid.

3. Fillmore C.J. (1978) "On the organization of semantic information in the lexicon". Parasession on the Lexicon, 148-173.

4. Fillmore C.J. (1998) "The mechanisms of "construction grammar". In Annual Meeting of the Berkeley Linguistics Society (Vol. 14, pp. 35-55).

5. Fillmore C.J. (1989) "Grammatical construction theory and the familiar dichotomies". In North-Holland Linguistic Series: Linguistic Variations (Vol. 54, pp. 17-38). Elsevier.

6. Kay P., \& Fillmore C.J. (1999) "Construction grammar and linguistic generalizations: The whats X doing Y? construction". Language, 75, 1-33.

7. Lewis M., Gough C., Martínez R., Powell M., Marks J., WOOLARD G.C., \& RIBISCH K.H. (1997) “Implementing the lexical approach: Putting theory into practice” (Vol. 3, No. 1, pp. 223-232). Hove: Language Teaching Publications.

8. Renkema J. (1999) "Introducción a los estudios sobre el discurso". Barcelona: Gedisa.

9. Schiffrin D. (2000) "Discourse markers: Language, meaning, and context". The handbook of discourse analysis, 1, 54-75.

10. Yagüe M.I. (2003) “Un modelo de control de acceso basado en la semántica”. RedIRIS: boletín de la Red Nacional de I+ D RedIRIS, (66), 63-66.

11. Zorraquino M., \& Portolés J. (1995) “Los marcadores del discurso”. Gramática descriptiva de la lengua española, 3, 4051-4213.

(с Рамирес Родригес Пабло (ramires-rodriges-p@rudn.ru)

Журнал «Современная наука: актуальные проблемы теории и практики»

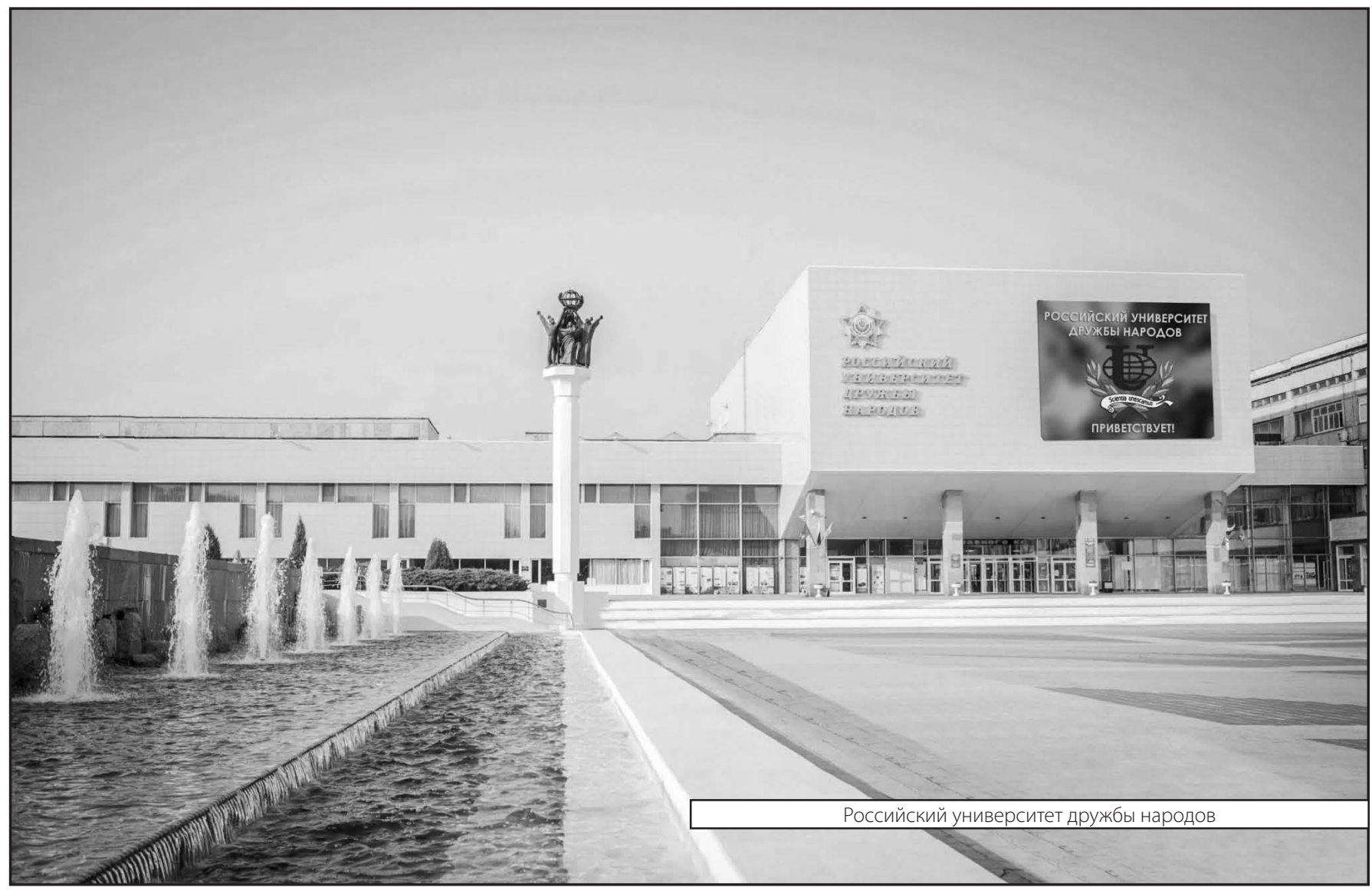

